dermatomyositis was made. Apart from persistent telangiectasia she completely recovered over the course of a year.

Ten years later, having been completely fit in the interim, she again developed similar symptoms affecting the skin and proximal muscle groups. Muscle biopsy showed non-specific changes only in the sections examined. Again without any drug therapy her symptoms resolved completely within a year.

She remained completely well until June 1981 when she presented to the Rheumatology Department with a further recrudescence of dermatomyositis, confirmed on skin biopsy and with an associated elevation of muscle enzymes (CPK $1677 \mathrm{U} / \mathrm{l}$, AST $78 \mathrm{U} / \mathrm{l}, \mathrm{HBD} 495 \mathrm{U} / \mathrm{l}$ ) and typical EMG findings supporting the diagnosis.

In view of the severity of this attack and despite the self-limiting nature of previous attacks she was treated with steroids and azathioprine, and two years later remains well on prednisolone $5 \mathrm{mg}$ daily and azathioprine $50 \mathrm{mg}$ b.d.

The prognosis of dermatomyositis is variable-about one third achieving complete remission or cure. Relapses, when they do occur, generally occur within a year of the initial attack. Recurrences separated by such long periods of remission are rare. Over the course of 34 years our patient has had three attacks of dermatomyositis, enjoying good health between attacks.

Department of Rheumatology,

Department of Dermatology,

JANE A. FOLEY

St Thomas's Hospital,

London SE1.

\section{Age distribution of amyloid in the intervertebral discs}

SIR, We have studied with interest the series of reports concerning amyloid deposits in joint tissues. ${ }^{1-3}$ In the excellent publication of Ladefoged ${ }^{4}$ the explanation of a negative correlation between amyloid and inflammation on the basis of Teilum's ${ }^{5}$ theory raises doubts, as inflammation is not necessarily found in osteoarthrosis. Moreover, the inflamed synovial membrane in rheumatoid arthritis only rarely exhibits amyloid deposits even in the burnt-out stage. On the other hand amyloid is known to occur in several tissues in senile individuals without an inflammatory process. Thus articular amyloid may also be regarded as an age-related phenomenon.

Some tissue components of the intervertebral discs are comparable to structures of diarthrodial joints. Inflammatory processes are usually regarded as unimportant for disc degeneration. We studied surgically removed disc specimens for the appearance of amyloid after Congo-red staining in two different age groups. The possibility that amyloid may even appear in 'ruptured fibrocartilage of vertebrae' has been reported by Bywaters and Dorling ${ }^{6}$ in a case of plasmocytoma and by Ballou et al. ${ }^{7}$ in primary amyloidosis.

As shown in Table 1, foci of an amyloid-like material with Congo-red green birefringence (Fig. la and b) were
Table 1 Incidence of congophilic deposits in surgically removed intervertebral discs

\begin{tabular}{llc}
\hline Age class & No. of classes & $\%$ Positive for amyloid \\
\hline$>65$ years & 80 & 36 \\
$<25$ years & 30 & 0
\end{tabular}

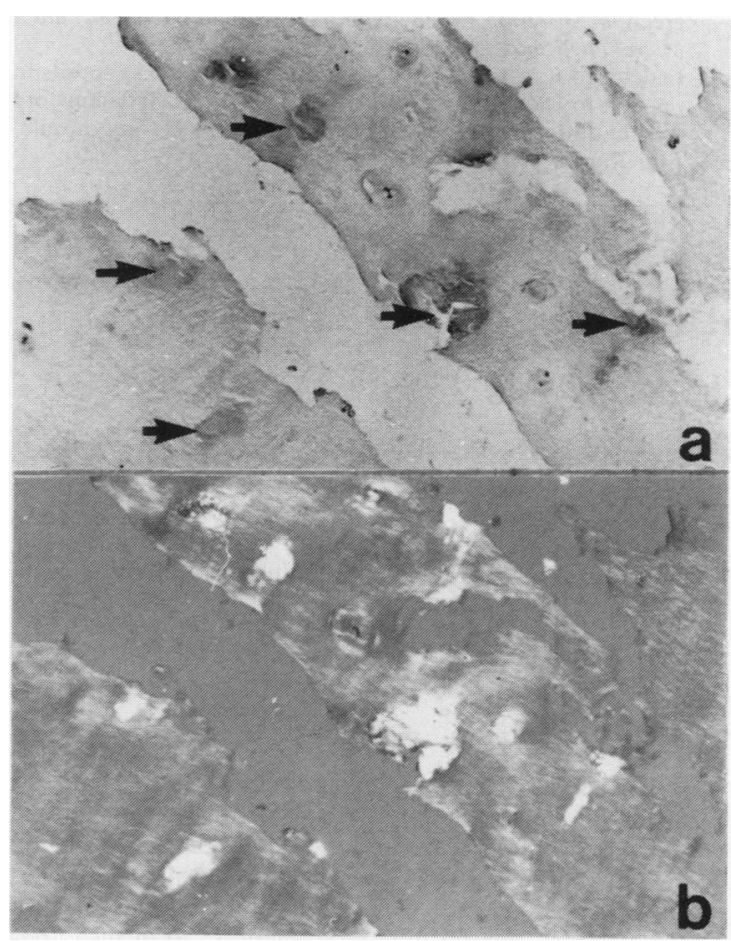

Fig. 1 Amyloid deposits (arrows) in surgically removed intervertebral discs. (a) Plain light, (b) polarised light. (Congo-red, $\times 88$ ).

present only in the fibrous and hyaline cartilage of the older individuals. The morphological pattern of amyloid distribution was very similar to the picture presented by Ladefoged $^{4}$ in the joint capsule with chondroid metaplasia. Therefore we favour the idea that amyloid in the diarthrodial joints resembles amyloid in the intervertebral discs, being merely an expression of senile amyloidosis as was also recently demonstrated by Shimizu et al. ${ }^{\times}$in the senescence-accelerated mouse.

Institute of Rheumatology,

TERESA WAGNER Warszawa/Poland.

Department of Pathology,

WINFRIED MOHR

University of Ulm,

\section{D-7900 Ulm/Donau}

Correspondence to Professor Dr W. Mohr, Department of Pathology, University of Ulm, Oberer Eselsberg. D-7900 Ulm/ Donau. West Germany. 


\section{References}

1 Christensen $\mathrm{H} \mathrm{E}$, Sorensen $\mathrm{K} \mathrm{H}$. Local amyloid formation of capsula fibrosa in arthrosis coxae. Acta Pathol Microbiol Scand [A] 1972; 80 (suppl 233): 128-31.

2 Teglbjaerg P S, Ladefoged C, Sorensen K H, Christensen H E. Local articular amyloid deposition in pyrophosphate arthritis. Acta Pathol Microbiol Scand [A] 1979; 87: 307-11.

3 Ladefoged C, Christensen H E. Congophilic substance with green dichroism in hip joints in autopsy material. Acta Patho Microbiol Scand [A] 1980; 88: 55-8.

4 Ladefoged C. Amyloid in osteoarthritic hip joints: deposits in relation to chondromatosis, pyrophosphate, and inflammatory cell infiltrate in the synovial membrane and fibrous capsule. Ann Rheum Dis 1983; 42: 659-64.
5 Teilum G. Pathogenesis of amyloidosis. The two phase cellular theory of local secretion. Acta Pathol Microbiol Scand /A/ 1964; 61: 21-45.

6 Bywaters E G L, Dorling J. Amyloid deposits in articular cartilage. Ann Rheum Dis 1970; 29: 294-306.

7 Ballou S P, Khan M A, Kushner I. Diffuse intervertebral disk calcification in primary amyloidosis. Ann Intern Med 1976; 85: 616-7.

8 Shimizu K, Ishii M, Yamamuro T, Takeshita S, Hosokawa M, Takeda T. Amyloid deposition in intervertebral discs of senescence-accelerated mouse. Arthritis Rheum 1982; 25: 7102 .

\section{Notes}

\section{Key words}

The use of key words has been introduced into Annals. Three to 10 key words or short phrases should be provided below the summary. They are to assist indexers in cross-indexing the article, and they should therefore not include words already in the title. When possible the terms used should be from the list of medical subject headings in the Index Medicus (MESH).

\section{Haemophilia prize}

The French Association of Haemophiliacs International Prize of French Fr 15000 , whose aim is to encourage medical research into the disease, will be awarded for the sixth time in July 1985. The regulations in French and English will be forwarded on request by the Secretariat of the selection committee (Association Française des Hémophiles, C.N.T.S., 6 rue Alexandre Cabanel, 75015 Paris, France. The work submitted for the prize must reach the secretariat of the selection committee by 15 March 1985 at the latest.

\section{Volvo awards for low back pain research}

To encourage research in low back pain the Volvo Company of Göteborg, Sweden, has sponsored three prizes of US $\$ 6000$ each. Awards will be made competitively on the basis of scientific merit in the following three areas: (1) clinical studies; (2) bioengineering studies; (3) studies in other basic science areas. Papers submitted for the contest must contain original material, not previously published or submitted for publication. Multiple authorship is acceptable. The manuscripts should be in the form of a complete report, not exceeding 30 typewritten pages, double-spaced, and in a form suitable for submission to a scientific journal. Five copies of each paper submitted in full should reach the address given below not later than 3 December 1984. One of the authors should be prepared, at his own expense, to come to Sydney, Australia, at the time of the meeting of the International Society for the Study of the Lumbar Spine, 14-18 April 1985, to present the paper and to receive the award. Further details from Professor Alf L. Nachemson, Department of Orthopaedic Surgery I, Sahlgren Hospital, S-413 45 Göteborg, Sweden.

\section{First world symposium on anti- phospholipid antibodies}

It is proposed to hold a symposium on clinical, biochemical, and immunological aspects of antiphospholipid antibodies on 5 October 1984 (fee (including catering) $£ 10 \cdot 00$ ). Recent studies have shown that antiphospholipid antibodies are clinically associated with thrombosis in SLE and lupus-like disorders. Other clinical associations may include recurrent abortion, thrombocytopenia, and CNS disease. Further details from Dr Graham R. V. Hughes, Rheumatology Unit, Royal Postgraduate Medical School, Hammersmith Hospital, Du Cane Road, London W12 OHS. 